\title{
Carbohydrate deficient glycoprotein syndrome type I: ophthalmic aspects in four Sicilian patients
}

\author{
A Fiumara, R Barone, P Buttitta, M Di Pietro, A Scuderi, F Nigro, J Jaeken
}

\begin{abstract}
-
Four patients with carbohydrate deficient glycoprotein (CDG) syndrome type I underwent ophthalmic examination. All of them had retinitis pigmentosa with extinguished scotopic electroretinogram. The importance of CDG syndromes as one of the metabolic causes of retinal dystrophy with 'bony spicule' pigment is stressed.
\end{abstract}

(Brf Ophthalmol 1994; 78: 845-846)

Carbohydrate deficient glycoprotein (CDG) syndromes are a newly recognised group of genetic multisystemic disorders characterised by partial deficiency of the carbohydrate moieties of glycoproteins. ${ }^{1}$ Three different types have been identified clinically and on the basis of the isoelectric focusing pattern of sialotransferrins. ${ }^{2}$

All patients have severe nervous system involvement, psychomotor retardation, ataxia, and, often, seizures and stroke-like episodes. Microcephaly, facial dysmorphism, thoracic deformities, limb atrophy, abnormal fat distribution, and ocular involvement are also frequently seen. ${ }^{2-4}$ We report the ophthalmic findings in four Sicilian patients with CDG syndrome type I aged from 9 to 21 years.

\section{Patients and methods}

Four patients from two families, with CDG type I, underwent extensive ophthalmic examination by standard methods. The diagnosis of CDG was suspected on the basis of the clinical features (facial dysmorphism, skeletal abnormalities, and severe olivopontocerebellar hypoplasia) and of the low levels of several serum glycoproteins (such as thyroxine binding globulin, haptoglobin, $\alpha_{1}$ acid glycoprotein, some clotting factors, etc). Isoelectric focusing of sialotransferrins showed the characteristic increase of asialotransferrin and disialotransferrin and a decrease of tetrasialotransferrin and pentasialotransferrin (Table 1).

FAMILY 1

The first two patients were brother and sister aged 21 and 19 years, respectively. Their clinical

Table 1 Serum sialotransferrin fraction (\%) from the patients compared with the range of controls

\begin{tabular}{llllll}
\hline $\begin{array}{l}\text { Sialotransferrin } \\
\text { fraction }\end{array}$ & Case 1 & Case 2 & Case 3 & Case 4 & Range \\
\hline 0 & 15 & $14 \cdot 3$ & $12 \cdot 8$ & 16 & $0-2$ \\
1 & $2 \cdot 7$ & 5 & $2 \cdot 9$ & $2 \cdot 6$ & $0-5$ \\
2 & 32 & 30 & $34 \cdot 0$ & $34 \cdot 4$ & $0-10$ \\
3 & $13 \cdot 7$ & 11 & $15 \cdot 5$ & $15 \cdot 7$ & $5-24$ \\
4 & $31 \cdot 7$ & 27 & $25 \cdot 3$ & 22 & $47-65$ \\
5 & 5 & $6 \cdot 2$ & $5 \cdot 8$ & $6 \cdot 8$ & $10-28$ \\
\hline
\end{tabular}

Table 2 Comparison of ocular findings in patients in this study with those reported in the literature

\begin{tabular}{llc}
\hline & $\begin{array}{l}\text { Patients } \\
\text { studied }\end{array}$ & $\begin{array}{l}\text { Patients } \\
\text { reported }\end{array}$ \\
\hline Low6
\end{tabular}

profiles were strikingly similar: they both had microcephaly, convergent squint, large and prominent jaw, keel thorax, ataxia, and mental retardation. Computed tomography (CT) revealed severe cerebellar hypoplasia with posterior fossa cyst. Ocular findings are summarised in Table 2.

Funduscopy showed chorioretinal dystrophy with 'bony spicule pigmentary deposits', this being more evident in the sister. Endocular tension was normal in the male but it was not possible to determine for the female as her severe mental retardation made her uncompliant. Visual acuity was lowered in both siblings; photopic ERG was normal and scotopic ERG absent in both. Visual evoked potential (VEP) amplitude was lowered to $20 \%$ and $50 \%$ respectively; latency was normal.

\section{FAMILY 2}

Cases 3 and 4 are two brothers aged 16 and 9 years. Horizontal nystagmus as well as convergent strabismus had been evident from the first few months of life in both patients. CT scan revealed a cyst occupying the posterior fossa and communicating with the fourth ventricle. Both brothers are now severely retarded and show typical CDG symptomatology.

Ocular findings (Table 2) were as follows:

Funduscopy revealed 'bony spicule' (Fig 1)

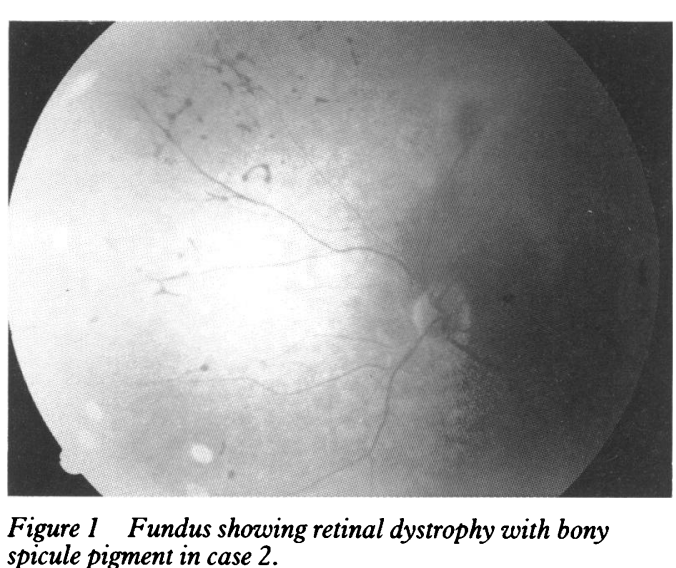

Department Department of Pediatrics, University of Catania, Viale A Italy.

Accepted for publication 7 July 1994 
chorioretinal dystrophy, scotopic flash ERG was extinguished in case 3 and greatly reduced in case 4. VEP amplitude was reduced to $50 \%$ and $20 \%$ respectively; latency was normal.

\section{Discussion}

Few reports have been published on the opthalmic aspects of CDG syndrome. ${ }^{13-5}$ The data are summarised in Table 2 and compared with those of our patients. A clinical review of 29 patients, aged 1 to 48 years, from Belgium, Norway, and Sweden revealed that they all showed alternating squint in the first year of life. ${ }^{1}$ Strømland studied 10 Swedish patients, ${ }^{34}$ five boys and five girls aged from 2 to 21 years, and also found esotropia in all regardless of their refractive status. Our patients had had a convergent squint since their first months of life. They all showed nystagmus and reduced VEP amplitude. This finding suggests that the optic nerve is involved rather than the ocular muscle innervation as suggested by Strømland.

Our patients also showed fundus changes typical of retinitis pigmentosa (see Fig 1), with extinguished scotopic ERG. Among the 10 patients reported by Strømland, five had retinitis pigmentosa, two had maculopathy, and one showed no macular reflex. Two other patients showed poor pigmentation of the macula with normal ERG. Andreasson $e a^{5} l^{5}$ reported retinitis pigmentosa in two out of five patients whereas ERG was abnormal in all. According to these authors, retinitis pigmentosa should be considered an age-related sign as it is present in the older patients and progresses with age. Clayton et $a l^{6}$ have recently reported a patient with CDG who had olivopontocerebellar atrophy (OPCA) and hypertrophic obstructive cardiomyopathy and died at 11 weeks of age. The patient already had retinal dystrophy and decreased ERG. In our first family, the fundus changes were more evident in the sister who also showed more severe neurological impairment compared with her brother's. Our case 2, as well as the patient reported by Clayton et al, suggests that the severity of retinal dystrophy is not a manifestation of age alone, but it is also related to the degree of clinical expression.

Degeneration of the sensory epithelium of the retina and the gradual extinction of the ERG occur in several metabolic encephalopathies. The pathophysiology of retinal damage in these disorders is still unclear. Toxic effects of the accumulated metabolites and/or energy deficit may be involved. Retinitis pigmentosa in CDG syndrome could be caused by a glycosylation defect involving the glycoproteins opsin and interphotoreceptor retinoid binding protein. ${ }^{5}$ This is supported by the post mortem findings in a 6-year-old boy, reported by Strømme $e t a l^{8}$ who found severe degeneration and loss of photoreceptors in the outer nuclear layer. Focal loss of pigment epithelium was also evident and migrated pigment cells were present in the photoreceptor layer.

We believe that in cases with early onset of strabismus followed by unexplained retinopathy, CDG syndrome should be taken into consideration and isoelectric focusing of sialotransferrins performed.

1 Jaeken J, Stibler H, Hagberg B. The carbohydrate-deficient glycoprotein syndrome. A new inherited multisystemic disease with severe nervous system involvement. Acta Paediatr Scand Suppl 375: [monograph] 1991.
Pasease

2 Jaeken J, Carchon $H$, Stibler $H$. The carbohydrateglycoprotein deficient syndromes. Pre-Golgi and Golgi disorders? Glycobiology 1993; 3: 423-8.

3 Kristiansson B, Andersson M, Tonnby B, Hagberg B. Disialotransferrin developmental deficiency syndrome. Arch Dis Child 1989; 64: 71-6.

4 Strømland K, Hagberg B, Kristiansson B. Ocular pathology in disialotransferrin developmental deficiency syndrome. Ophthalmol Pediatr Genet 1990; 11: 309-13.

5 Andreasson S, Blennow G, Ehinger B, Strømland K. Full field electroretinograms in patients with the carbohydratedeficient glycoprotein syndrome. Am f Ophthalmol 1991; 112: 83-6.

6 Clayton PT, Winchester BG, Keir G. Hypertrophic obstructive cardiomyopathy in a neonate with carbohydrate-deficient glycoprotein syndrome. F Inher Metab Dis 1992; 15: 857-961.

7 Pol-The BT, Billette de Villemeur T, Abitbol M, Dufier JL, Saudubray JM. Metabolic pigmentary retinopathies: diagno-
sis and therapeutic attempts. Eur f Pediatr 1992; 151: 2-11.

8 Strømme P, Mahelen J, Strom EH, Torvik A. Post mortem findings in two patients with the carbohydrate-deficient glycoprotein syndrome. Acta Paediatr Scand 1991; 375 (suppl): 55-62. 